\title{
RETRACTED ARTICLE: Neural-network-based unified particle swarm optimization for the prediction of asphaltene precipitation due to natural depletion
}

\author{
Mohammad Ali Ahmadi • Seyed Reza Shadizadeh
}

Received: 30 November 2011/ Accepted: 16 March 2012/Published online: 18 April 2012

(C) Springer-Verlag London Limited 2012

This article has been retracted at the request of the author, following concerns over the paper's integrity.

M. A. Ahmadi ( $\square)$

Department of Petroleum Engineering,

Ahwaz Faculty of Petroleum Engineering, Petroleum University

of Technology, P.O.BOX:63431, Kut Abdollah, Ahwaz, Iran

e-mail: ahmadi6776@yahoo.com

S. R. Shadizadeh

Department of Petroleum Engineering,

Abadan Faculty of Petroleum Engineering,

Petroleum University of Technology, Abadan, Iran 